\title{
Calcium and vitamin $D$ intake by postmenopausal women with osteoporosis in Spain: an observational calcium and vitamin $D$ intake (CaVIT) study
}

\author{
This article was published in the following Dove Press journal: \\ Clinical Interventions in Aging \\ 15 June 2013 \\ Number of times this article has been viewed
}

\author{
Tao Fan' \\ Gonzalo Nocea ${ }^{2}$ \\ Ankita Modi ${ }^{3}$ \\ Leah Stokes' \\ Shuvayu S Sen' \\ 'Global Outcomes Research, Merck \& \\ Company, Whitehouse Station, \\ NJ, USA; ${ }^{2}$ Department of Outcomes \\ Research, Merck, Sharp and Dohme \\ Spain, Madrid, Spain; ${ }^{3}$ Global Human \\ Health, Outcomes Research, Merck \& \\ Company, Whitehouse Station, \\ NJ, USA
}

\begin{abstract}
Background: Osteoporotic fractures are important causes of morbidity, mortality, and increased health care costs. However, the risk of osteoporotic fractures can be decreased, with clinical studies supporting the use of calcium and vitamin D supplements to promote bone health. Vitamin D insufficiency is widespread, particularly among postmenopausal women with osteoporosis, and this indicates that dietary intake is suboptimal, even though vitamin D supplements are widely available.
\end{abstract}

Methods: We conducted an observational study, using telephone surveys, to estimate vitamin D and calcium intake and the use of prescription osteoporosis medications in Spanish women aged $\geq 50$ years with osteoporosis.

Results: Among the study participants, mean dietary calcium intake was $1239 \mathrm{mg} /$ day and generally appeared sufficient in terms of the recommended daily intake guidance documents. Participants aged $\geq 75$ years had a significantly lower mean dietary calcium intake ( $988 \mathrm{mg} /$ day), thus one-half were below the level advised by the World Health Organization. Daily calcium intake was also lower in participants who were not taking prescription medications for bone health. Dietary vitamin D intake was 167 IU/day, which is well below both the established target dose (400 IU/day) and the more recent, higher guideline recommended for postmenopausal women (800-1300 IU/day). Dietary vitamin D intake was even lower for participants aged $\geq 75$ years (120 IU/day) and was not related to the use of bone health prescription medications.

Conclusion: These results support the need for greater promotion of the benefits of higher vitamin D intake in Spanish women with osteoporosis.

Keywords: osteoporotic fractures, prescription osteoporosis medications, dietary supplements, recommended dietary intake

\section{Background}

Osteoporotic fractures are common in women aged $\geq 50$ years but are potentially preventable. The lifetime risk of fracture is $>50 \%$ for women at age 50 and is $>20 \%$ for men of the same age, ${ }^{1}$ with such fractures estimated to affect 20 million Europeans. ${ }^{2,3}$ Osteoporotic fractures are associated with serious complications and contribute to an increase in mortality rates of up to $20 \%$ in the elderly. ${ }^{4}$

Osteoporosis presents a considerable health burden for individual European countries. In Spain, postmenopausal women experience a lifetime fracture risk of $50.4 \%{ }^{5}$ the prevalence of osteoporotic hip fracture is about 7.20 per 1000 people aged $\geq 60$ years, with $74 \%$ of sufferers being women and $26 \%$ being men. ${ }^{6}$ The total annual direct cost of hospitalization for hip fractures in Spain was about 216 million Euros in $1996 .^{7}$
Correspondence: Tao Fan

Global Outcomes Research, Merck \& Company, PO Box 100 , One Merck Drive, WS2E-76, Whitehouse Station, NJ 08889, USA $\mathrm{Tel}+$ I 9084234627

Fax + I 908735 I688 Email tao_fan@merck.com 
Adequate calcium and vitamin D are indispensable for maintaining bone health. Dietary calcium is required for normal calcium balance and prevents bone loss due to dietary deficiency. Study findings support a role for calcium and vitamin D supplementation in osteoporosis treatment, as the diets of many osteoporotic patients are deficient in one or both. ${ }^{8}$ Serum levels of the active metabolite 25-hydroxyvitamin D are the best way to assess vitamin D sufficiency. Serum levels of 25-hydroxyvitamin D are correlated with bone mineral density in many studies. ${ }^{9-11}$ However, key to achieving bone health benefits is the use of an appropriate vitamin $\mathrm{D}$ dose, with a daily dose of at least 700-800 IU recommended to produce adequate serum 25-hydroxyvitamin D. ${ }^{12}$ Similar favorable effects on bone mass and, in some studies, fracture risk have been associated with calcium ${ }^{13,14}$ and vitamin D plus calcium ${ }^{15-17}$ supplementation of nutritionally deficient populations.

As there are few natural food sources of vitamin D, the failure of postmenopausal women with osteoporosis to take sufficient vitamin D supplements can result in vitamin D inadequacy. ${ }^{18}$ Studies conducted in various European countries showed that a substantial proportion of patients with osteoporosis, ranging from $32.1 \%{ }^{19}$ to $81.6 \%,{ }^{20}$ have suboptimal serum 25-hydroxyvitamin D levels. ${ }^{19-22}$ Widespread vitamin $\mathrm{D}$ insufficiency in patients with osteoporosis may be due to a number of factors, including the biological consequences of aging, lack of sun exposure, and limited awareness of the importance of vitamin D supplementation by both patients and their physicians. ${ }^{18,23}$

At present, there are limited data on the dietary and supplemental intake of vitamin D and calcium in patients with osteoporosis. The objective of this study was to assess vitamin D and calcium intake, from both food and dietary supplements, in Spanish females aged $\geq 50$ years with osteoporosis.

\section{Methods}

\section{Study participants}

Spanish physicians (107) were identified using national stratified physician lists purchased from national councils and the local national health system. The physicians were contacted and those willing to participate in the study were asked to refer their qualifying patients with osteoporosis who were subsequently contacted by telephone. Patients interested in participating in the study were asked to phone a toll-free number for additional information and to determine whether they qualified. Inclusion criteria included being a female aged $\geq$ 50 years diagnosed with postmenopausal osteoporosis, and whose residence was in Spain. The study design and question- naire were reviewed and approved by the Essex Institutional Review Board (Lebanon, NJ, USA). Respondents who met the inclusion criteria were read a statement of informed consent. This statement included a brief description of the study, its voluntary nature, participant confidentiality, and contacts for specific questions about participants' health conditions, participants' rights, and general information about the study. Those who did not provide informed consent to participate in the study were excluded. The study was conducted by a third-party contract research organization.

It was determined that a sample size of 207 was required to detect a statistically significant difference $(5 \%$ level of significance) in mean population calcium intakes, assuming a mean standard deviation [SD] intake of 1200 (577) mg/day, the effect size of $100 \mathrm{mg} /$ day yields $80 \%$ power for a sample size of $\mathrm{N}=207$ at $5 \%$ level of significance.

\section{Survey questions}

The survey was conducted by trained, native Spanishspeaking interviewers; an average of 15 minutes was given to participants for survey completion. Questions were drafted in English and translated into Spanish. Subsequently, the questions were translated back into English to ensure that the questions had been accurately translated.

Survey responses provided information on prescribed osteoporosis medications, calcium, and vitamin D intake from the diet and supplements. Participants were asked, "Are you currently taking prescription medication(s) for your bone health?" If their answer was affirmative, they were asked, "What prescription medication(s) are you currently taking for bone health?" Participants were also asked to describe the frequency with which they consumed certain foods, using the Supplementation en Vitamines et Mineraux Antioxydants (SU.VI.MAX) food-frequency questionnaire; ${ }^{24}$ a list of the most common foods consumed was broken down by type. Participants were also asked eight questions about their use of vitamin and mineral supplements, including calcium or calcium-containing antacids. They were asked if they took multivitamins regularly and, if so, how often (possible responses: every day, 4-6 days per week, 1-3 days per week, $1-3$ days per month, and $<1$ day per month). Participants were asked if the calcium products contained vita$\mathrm{min} \mathrm{D}$ and were prompted to look at the package label to report the calcium dosage ( $<500 \mathrm{mg}, 500-599 \mathrm{mg}, 600-999 \mathrm{mg}$, $\geq 1000 \mathrm{mg}$ ). Participants were also asked, "During the past month, have you sunbathed or travelled to a sunny climate or region?" and "During the past month, on average, how many hours per week did you spend outside without and with sun protection (sunscreen or protective clothing)?" Of the twelve 
questions, two were from the National Health and Nutrition Examination Survey (NHANES) to facilitate validation. ${ }^{25}$

The questionnaires included a vitamin $\mathrm{D}$ assessment component from the Health Habits and History Questionnaire (HHHQ), the Spanish Food Frequency Questionnaire (FFQ), and a short survey on calcium and vitamin D intake. ${ }^{24,26}$ The HHHQ is a selfadministered diet history questionnaire. It has been validated for use in epidemiological and clinical studies. The FFQ consist of questions on frequency of intake of foods such as dairy, eggs, meat, fish, vegetables, fruit, legumes, fats, sweets and pastries, drinks, pre-cooked or pre-prepared food, and miscellaneous food. Possible responses included, "never," "'yearly," "monthly," "weekly," or "daily." The Spanish FFQ has been validated and used in previous epidemiological studies. ${ }^{27,28}$

Published references were used to determine the calcium and/or vitamin D content per food serving and the number of required servings per listed item. ${ }^{24,29}$ The average daily intake of calcium and vitamin D per serving for each food item was computed as: (calcium or vitamin $\mathrm{D}$ content) $\times$ (times per year/365), (calcium or vitamin $\mathrm{D}$ content $) \times($ times per month/30), (calcium or vitamin $\mathrm{D}$ content $) \times($ times per week $/ 7$ ), or (calcium or vitamin D content $) \times($ times per day). Daily values for all foods were then added to achieve the total daily intake of calcium and vitamin $\mathrm{D}$.

Daily calcium intake from calcium or calcium-containing antacids was computed as reported daily elemental calcium intake at $<800 \mathrm{mg}, 800-1200 \mathrm{mg}$, or $\geq 1200 \mathrm{mg}$. Respondents who regularly used a standard multivitamin typically received 400 IU vitamin D, and daily vitamin D intake from supplements was computed as daily use at $<200$ IU, 200-400 IU, or $<400$ IU.

\section{Statistical analysis}

Mean daily calcium and vitamin D intake were computed. A one-sample $t$-test was performed to estimate whether the mean daily vitamin $\mathrm{D}$ intake was significantly lower than the recommended average daily dose of $400 \mathrm{IU} /$ day. ${ }^{30}$ A similar analysis was done to estimate whether the sample mean daily calcium intake was significantly lower than the $800 \mathrm{mg}$ recommended daily dose. ${ }^{31}$ To identify factors associated with calcium and vitamin D intake, in addition to their relative effects, least squares regressions were conducted. Fisher's exact tests were used to analyze the differences of vitamin $\mathrm{D} /$ calcium intake in patients on different prescribed medications for bone health and the differences of vitamin $\mathrm{D} /$ calcium intake from diets in patients among different age groups.

\section{Results \\ Patient characteristics}

Of the 207 women who participated, 62.8\% were aged 50-64 years, $20.8 \%$ were aged $65-74$ years, and $16.4 \%$ were aged $\geq 75$ years.

\section{Vitamin $D$ intake from food}

The mean (SD) intake of vitamin D from food was 167 $( \pm 87)$ IU/day (Table 1), which is notably less than the recommended daily dose of $400 \mathrm{IU} /$ day. Vitamin D intake was not significantly different $(P=0.114)$ in patients taking bisphosphonates (186 $\pm 92 \mathrm{IU} /$ day) compared with those taking non-bisphosphonates (156 $\pm 64 \mathrm{IU} /$ day) or no prescription medications for bone health $(148 \pm 85 \mathrm{IU} /$ day $)$.

\section{Supplemental vitamin D and multivitamin use}

Of those participants who derived 200-400 IU/day of vitamin $\mathrm{D}$ from their diets, $68 \%$ reported taking a multivitamin with vitamin D and 54\% reported taking supplemental vitamin D alone (Figure 1). Use of a multivitamin with vitamin $\mathrm{D}$ and supplemental vitamin $\mathrm{D}$ alone by groups

Table I Daily vitamin D intake from food

\begin{tabular}{|c|c|c|c|c|c|c|}
\hline \multirow[t]{2}{*}{ Characteristic } & \multicolumn{6}{|c|}{ Daily vitamin D intake from food } \\
\hline & $\mathbf{N}$ & Mean (SD) & $<200$ IU & 200-400 IU & $>400 \mathrm{IU}$ & $P^{a}$ \\
\hline Overall & 207 & 167 (87) & $23 \%$ & $45 \%$ & $32 \%$ & \\
\hline Medications $^{\mathrm{b}}$ & & & & & & 0.114 \\
\hline Bisphosphonates & 93 & $186(92)$ & $60 \%$ & $38 \%$ & $2 \%$ & \\
\hline Non-bisphosphonates & 70 & $156(64)$ & $74 \%$ & $26 \%$ & $0 \%$ & \\
\hline No treatment & 29 & | $48(85)$ & $76 \%$ & $21 \%$ & $3 \%$ & \\
\hline Age (from diet) & & & & & & 0.034 \\
\hline $50-64$ & 130 & 177 (77) & $64 \%$ & $35 \%$ & $1 \%$ & \\
\hline $65-74$ & 43 & $176(115)$ & $67 \%$ & $26 \%$ & $7 \%$ & \\
\hline$\geq 75$ & 34 & $120(65)$ & $82 \%$ & $18 \%$ & $0 \%$ & \\
\hline
\end{tabular}

Notes: ap values are based on Fisher's exact test; ${ }^{b}$ nine participants reported having taken medication but did not know what it was. Abbreviation: SD, standard deviation. 


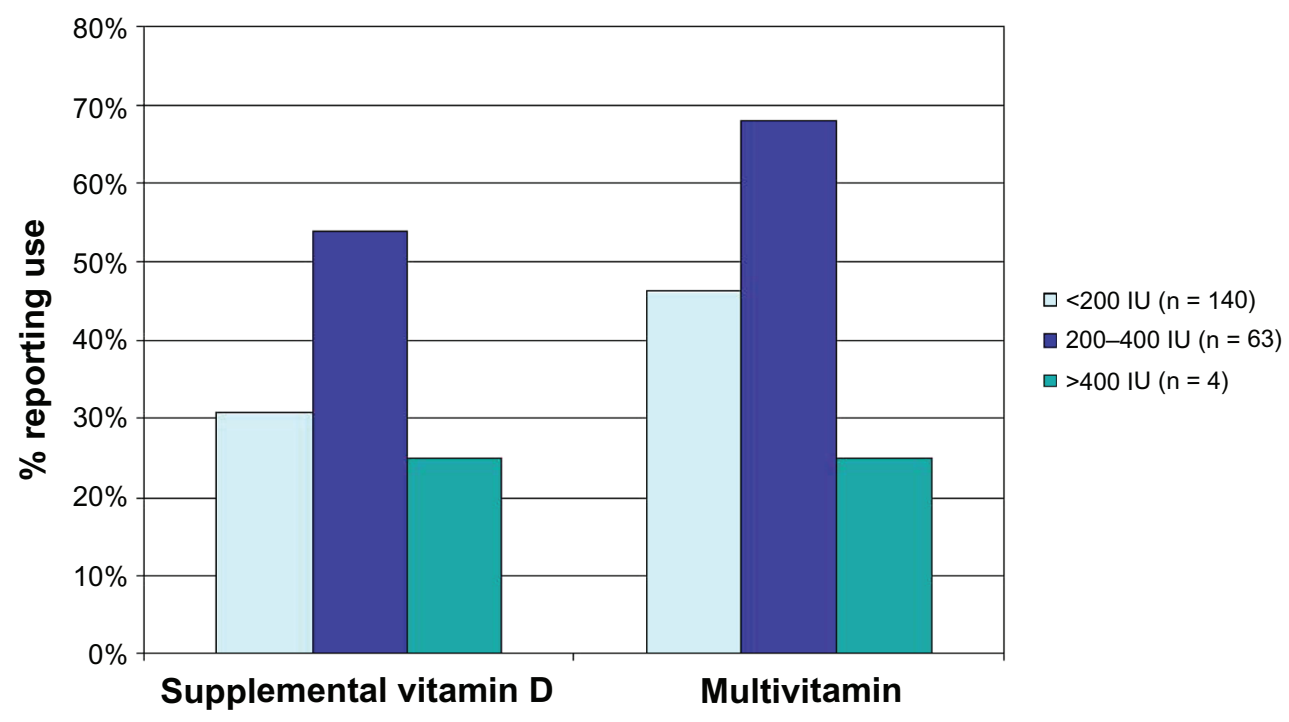

Figure I Supplemental vitamin D and multivitamin use by daily dietary vitamin D intake.

obtaining $<200 \mathrm{IU} /$ day and $>400 \mathrm{IU} /$ day from their diet was notably lower, as shown in Figure 1. When considered by age group, women aged $\geq 75$ years reported a significantly lower mean daily intake of vitamin D from food (120 \pm 65 IU/day versus $177 \pm 77 \mathrm{IU} /$ day for the $50-64$ years age group and $176 \pm 115 \mathrm{IU} /$ day for the $65-74$ years age group; $P=0.034)$ (Table 1).

\section{Calcium intake from food}

The mean (SD) calcium intake from food was $1239( \pm 457)$ $\mathrm{mg}$ /day (Table 2), which was notably higher than the recommended daily dose of $800 \mathrm{mg} /$ day. Daily calcium intake was also significantly lower $(P=0.037)$ in patients not taking prescription medications for bone health $(1054 \pm 336 \mathrm{mg} /$ day $)$ compared with those taking bisphosphonates $(1365 \pm 448 \mathrm{mg} /$ day) or non-bisphosphonates (1167 $\pm 432 \mathrm{mg} /$ day $)$.

The predominant sources of dietary calcium were dairy products (mean $477.4 \mathrm{mg}$ ) and vegetables $(371.3 \mathrm{mg}$ ), with more participants taking milk every day than the other major sources of calcium (Table 3 ). The proportion of participants eating a portion each day of all major calcium sources was higher for those with a daily calcium intake of more than $800 \mathrm{mg}$.

\section{Supplemental calcium and multivitamin use by dietary calcium intake}

Of those participants who derived $<800 \mathrm{mg} /$ day of calcium from their diet, $67 \%$ reported taking a multivitamin with calcium and 50\% reported taking supplemental calcium alone (Figure 2). Similar incidences of multivitamin with calcium, and supplemental calcium alone use were seen in participants obtaining $800-1200 \mathrm{mg} /$ day and $\geq 1200 \mathrm{mg} /$ day from their diet, as shown in Figure 2. When considered by age group, women aged $\geq 75$ years reported a significantly lower mean daily intake of calcium from food $(988 \pm 346 \mathrm{mg}$ /day versus $1314 \pm 461 \mathrm{mg} /$ day for the 50-64 age group and

Table 2 Daily calcium intake from food

\begin{tabular}{|c|c|c|c|c|c|c|}
\hline \multirow[t]{2}{*}{ Characteristic } & \multicolumn{6}{|c|}{ Daily calcium intake from food } \\
\hline & $\mathbf{N}$ & Mean (SD) & $<800 \mathrm{mg}$ & $800-1200 \mathrm{mg}$ & $>1200 \mathrm{mg}$ & $P^{a}$ \\
\hline Overall & 207 & $1239(457)$ & $28 \%$ & $53 \%$ & $19.3 \%$ & \\
\hline Medications ${ }^{\mathrm{b}}$ & & & & & & 0.037 \\
\hline Bisphosphonates & 93 & I 365 (448) & $10 \%$ & $28 \%$ & $62 \%$ & \\
\hline Non-bisphosphonates & 70 & I I 67 (432) & $19 \%$ & $37 \%$ & $44 \%$ & \\
\hline No treatment & 29 & $1054(336)$ & $28 \%$ & $34 \%$ & $38 \%$ & \\
\hline Age (from diet) & & & & & & $<0.0001$ \\
\hline $50-64$ & 130 & I3I4 (46I) & $11 \%$ & $29 \%$ & $60 \%$ & \\
\hline $65-74$ & 43 & $1209(460)$ & $19 \%$ & $42 \%$ & $40 \%$ & \\
\hline$\geq 75$ & 34 & $988(346)$ & $41 \%$ & $32 \%$ & $26 \%$ & \\
\hline
\end{tabular}

Notes: $P$ values are based on Fisher's exact test; ${ }^{b}$ nine participants reported having taken medication but did not know what it was. Abbreviation: SD, standard deviation. 
Table 3 Contributors to dietary calcium intake

\begin{tabular}{|c|c|c|c|}
\hline \multirow[t]{2}{*}{ Food } & \multicolumn{3}{|c|}{ Daily calcium intake } \\
\hline & $\begin{array}{l}\text { Mean daily } \\
\text { intake (mg) }\end{array}$ & $\begin{array}{l}<800 \mathrm{mg} \\
(\mathrm{n}=\mathrm{I} I \mathrm{I})\end{array}$ & $\begin{array}{l}\geq 800 \mathrm{mg} \\
(\mathrm{n}=36)\end{array}$ \\
\hline Dairy & 477.4 & & \\
\hline Skim milk & 90.9 & $72 \%$ & $90 \%$ \\
\hline Semi-cured cheese & 85.1 & $0 \%$ & $13 \%$ \\
\hline Vegetables & 371.3 & & \\
\hline Swiss chard, spinach & 100.4 & $0 \%$ & $30 \%$ \\
\hline $\begin{array}{l}\text { Endive, lettuce, } \\
\text { escarole }\end{array}$ & 80.9 & $22 \%$ & $64 \%$ \\
\hline Fruit and nuts & 160.7 & & \\
\hline $\begin{array}{l}\text { Almonds, walnuts, } \\
\text { peanuts }\end{array}$ & 27.7 & $36 \%$ & $75 \%$ \\
\hline Orange, grapefruit & 38.6 & $3 \%$ & $23 \%$ \\
\hline
\end{tabular}

$1209 \pm 460 \mathrm{mg} /$ day for the $65-74$ age group; $P<0.0001)$ (Table 2).

Of the participants who reported taking a calcium supplement, $31.3 \%$ reported taking $<500 \mathrm{mg}$ daily, $30.4 \%$ reported taking 500-599 mg, 8.9\% reported taking 600-999 mg, $10.7 \%$ reported taking $>1000 \mathrm{mg}$, and $18.8 \%$ reported not knowing how much they were taking. In addition, $69.6 \%$ of those participants who reported taking calcium supplements also reported that the calcium products contained vitamin D.

\section{Discussion}

The results of this observational study in postmenopausal Spanish women indicate a high prevalence of insufficient vitamin D intake (mean $167 \mathrm{IU} /$ day from food) in women with osteoporosis, particularly in those aged $\geq 75$ years. Although the amount of vitamin D obtained from supplements was not specified in this study, the low proportion of subjects taking supplements and multivitamins combined with a low dietary intake supports this conclusion. In fact, these results are likely to underestimate the prevalence of vitamin D insufficiency, because a low threshold for vitamin D sufficiency (400 IU/day) was applied. In contrast, Food and Agriculture Organization of the United Nations/World Health Organization guidelines recommend a minimum vitamin $\mathrm{D}$ intake of $600 \mathrm{IU} /$ day for women aged $>65$ years. ${ }^{32}$ More recent European guidelines recommend a minimum intake of $800 \mathrm{IU}$ per day to reduce fracture risk. ${ }^{30}$

In contrast, the mean dietary calcium intake in postmenopausal Spanish women was higher $(1239 \mathrm{mg} /$ day $)$ than the recommended daily dose of $800 \mathrm{mg} /$ day, and was comparable across all age groups assessed. This daily intake of calcium is consistent with the level recommended in the "Nutritional objectives for the Spanish population." ${ }^{31}$ Calcium intake from food was significantly higher in participants taking osteoporosis medications. Calcium supplementation occurred with comparable frequency in women irrespective of their dietary calcium intake. The target calcium intake level of $800 \mathrm{mg} /$ day used in this study is lower than the $1300 \mathrm{mg}$ /day recommended by the Food and Agriculture Organization of the United Nations/World Health Organization for postmenopausal women; ${ }^{32}$ however, only postmenopausal Spanish women aged $\geq 75$ years had a dietary calcium intake substantially below this higher target.

\section{Comparison with literature findings}

A number of recent studies have also shown suboptimal vitamin D intake in elderly Spanish populations ${ }^{33,34}$ and

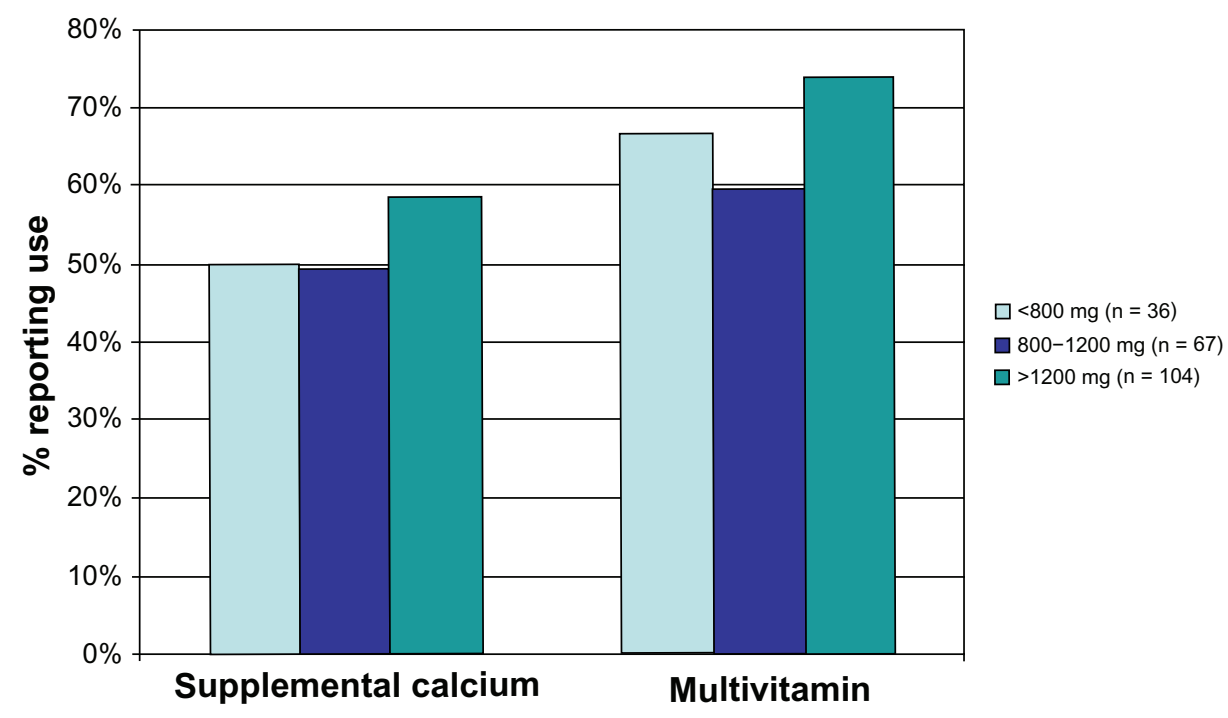

Figure 2 Supplemental calcium and multivitamin use by daily dietary calcium intake. 
in various groups of postmenopausal Spanish women. ${ }^{35-37}$ However, the findings reported in this study are somewhat at odds with those presented in a recent study conducted in postmenopausal European women with osteoporosis or osteopenia. ${ }^{19}$ Despite a high prevalence of vitamin D inadequacy in European subjects, Bruyère et al showed a mean 25-hydroxyvitamin D level of $85.2( \pm 33.3) \mathrm{nmol} / \mathrm{L}$ in Spanish subjects, a level well above all recommended cutoffs. ${ }^{19}$ This mean value did, however, equate to low 25 -hydroxyvitamin D levels for $45.8 \%$ of Spanish participants. The finding of more widespread vitamin D inadequacy in our study could result from the absence of any assessment of the contribution of endogenous vitamin D synthesis following exposure to sunlight; Bruyère et al noted that levels of 25-hydroxyvitamin D were significantly different when sampling occurred in winter than when it occurred during the summer months. ${ }^{19}$

The literature considering dietary calcium intake in Spanish populations shows considerable variability. Bruyère et al reported a dietary intake of $1074 \mathrm{mg} /$ day for postmenopausal Spanish women with osteoporosis, ${ }^{19}$ which is not substantially different from our finding. Their study went on to identify that the majority of dietary calcium ingested was derived from dairy sources, consistent with previous reports. $^{38,39}$ In contrast, other studies report a lower mean daily calcium intake, of approximately $800 \mathrm{mg}$, for elderly/ postmenopausal women in various regions of Spain. ${ }^{34,35,37}$ These studies assessed nutrient levels in specific areas of Spain, raising the prospect that regional variation in dietary patterns probably affects calcium intake.

\section{Methods of improving vitamin $D$ sufficiency}

In our study, vitamin D intake from food was not notably different in women who did or did not receive prescribed medication for osteoporosis. This finding is somewhat surprising, given that women regularly taking such treatments might be expected to be more aware of other methods of optimizing their bone health. Vitamin D supplementation could help to promote bone health in Spanish women with osteoporosis. $^{34,35}$

\section{Study limitations}

There are several limitations inherent in our study design. The study was observational in its nature and, although likely to be reflective of usual-care practice, may be subject to selection bias. Results may be biased by the use of a convenience sample and by the selection of patients who consented to the study and contacted the interviewers: these patients may be more aware of their health needs, more motivated to seek care, and/or have more favorable views of their health care compared with patients who did not agree to participate. This disparity may have led to our underestimating the actual level of vitamin D inadequacy in Spanish postmenopausal women. In addition, the study results are based on patient self-report, which is subject to the influence of memory and other subjective factors.

Although $69.6 \%$ of participants reported that their calcium supplements contained vitamin $\mathrm{D}$, this study did not ask participants to quantify the amount of vitamin D contained in the calcium supplements. The amounts of vitamin D in the vitamin D supplements were also not specified, thus the total daily intake of vitamin D from both food and supplements could not be estimated.

The data consider the dietary intake of both vitamin $\mathrm{D}$ and calcium rather than serum levels of the active components. Endogenous synthesis following exposure to sunlight is a major source of vitamin D. ${ }^{40}$ Our study did not assess different levels of exposure to sunlight, which are known to affect serum levels of 25-hydroxyvitamin D. ${ }^{33,35}$ In addition, our study did not assess different types of diets. A recent study showed that calcium absorption and utilization are influenced by dietary composition, with a Mediterranean diet potentially favoring nutrient utilization to a greater extent than other diets. ${ }^{41}$ In a study by Mataix et al, $40 \%$ of individuals participating in a survey in Southern Spain had a low calcium intake, yet plasma calcium concentrations were below the reference range in only $15 \% .{ }^{42}$

The extent to which our results apply to the general European population is unclear, and the findings cannot be extrapolated to men with osteoporosis. Elderly men are also at high risk of developing osteoporosis, ${ }^{1,6}$ with the resulting fractures being associated with substantial morbidity and mortality. ${ }^{43}$

Future studies are needed to better define the optimal use of vitamin D supplements in promoting bone health and preventing osteoporotic fractures. Some previous studies have failed to demonstrate a significant benefit for vitamin D supplementation on fracture risk. ${ }^{44,45}$ For example, in a study of postmenopausal women recruited to a Women's Health Initiative trial with or without osteoporosis, calcium plus vitamin D supplementation increased hip bone mineral density. ${ }^{44}$ However, a significant effect of supplementation on the incidence of hip fracture was observed only after data from non-treatment-compliant subjects were censored. In the Randomised Evaluation of Calcium Or vitamin D (RECORD) trial, calcium and/or vitamin D supplementation did not 
significantly reduce the incidence of low-energy fracture. ${ }^{45}$ A limitation of both studies was the inclusion of subjects who had not been diagnosed with osteoporosis. In addition, the Women's Health Initiative highlights the importance of achieving sufficiently high vitamin D intake, which is increasingly being cited as instrumental to optimizing bone health benefits. ${ }^{44}$

\section{Conclusion}

Inadequate vitamin $\mathrm{D}$ intake is common among postmenopausal women with osteoporosis in Spain. Further initiatives, including improved patient education, lifestyle, and vitamin D supplementation or pharmacotherapy, are needed to promote adequate vitamin $\mathrm{D}$ intake in elderly populations to avoid serious adverse consequences for bone health.

\section{Authors' contributions}

TF, SS, and GN conceived and designed the study. TF performed statistical analyses. AM and LS led data presentation and report drafting. All authors contributed to the interpretation of study data, the intellectual content of the report, and approval of the final manuscript.

\section{Acknowledgments}

Study funding was provided by Merck \& Company, Inc. We thank Melissa Stauffer, PhD, Lauren Weisenfluh, and Dimitra Panagiotoglou, all in affiliation with SCRIBCO, for medical writing assistance.

\section{Disclosure}

All the authors are employees of Merck \& Company, Inc.

\section{References}

1. van Staa TP, Dennison EM, Leufkens HG, Cooper C. Epidemiology of fractures in England and Wales. Bone. 2001;29(6):517-522.

2. Johnell O, Kanis JA. An estimate of the worldwide prevalence and disability associated with osteoporotic fractures. Osteoporos Int. 2006; 17(12):1726-1733.

3. International Osteoporosis Foundation (IOF). Osteoporosis in the EU: Improving the Assessment of Fracture Risk. Nyon: IOF; 2006. Available from: http://www.iofbonehealth.org/sites/default/files/PDFs/EU\%20 Reports/eu-report-2006.pdf. Accessed March 11, 2013.

4. Melton LJ 3rd. Adverse outcomes of osteoporotic fractures in the general population. J Bone Miner Res. 2003;18(6):1139-1141.

5. Reyes Balaguer J, Moreno Olmos J. Prevalence of osteopenia and osteoporosis in postmenopausal women. Aten Primaria. 2005;35(7):342-345. Spanish.

6. Herrera A, Martínez AA, Ferrandez L, Gil E, Moreno A. Epidemiology of osteoporotic hip fractures in Spain. Int Orthop. 2006;30(1):11-14.

7. European Commission. Report on Osteoporosis in the European Community: Action for Prevention. Luxembourg: Office for Official Publications of the European Commission; 1998. Available from: http://www.iofbone health.org/sites/default/files/PDFs/EU\%20Reports/ eu_report_1998.pdf. Accessed March 11, 2013.
8. Lips $\mathrm{P}$, Bouillon R, van Schoor NM, et al. Reducing fracture risk with calcium and vitamin D. Clinical Endocrinol (Oxf). 2010;73(3):277-285.

9. Malavolta N, Pratelli L, Frigato M, Mulè R, Mascia ML, Gnudi S. The relationship of vitamin $\mathrm{D}$ status to bone mineral density in an Italian population of postmenopausal women. Osteoporos Int. 2005;16(12): 1691-1697.

10. Bischoff-Ferrari HA, Dietrich T, Orav EJ, Dawson-Hughes B. Positive association between 25-hydroxy vitamin D levels and bone mineral density: a population-based study of younger and older adults. Am J Med. 2004;116(9):634-639.

11. von Mühlen DG, Greendale GA, Garland CF, Wan L, Barrett-Connor E. Vitamin D, parathyroid hormone levels and bone mineral density in community-dwelling older women: the Rancho Bernardo Study. Osteoporos Int. 2005;16(12):1721-1726.

12. Bischoff-Ferrari H. Vitamin D: what is an adequate vitamin D level and how much supplementation is necessary? Best Pract Res Clin Rheumatol. 2009;23(6):789-795.

13. Cumming RG. Calcium intake and bone mass: a quantitative review of the evidence. Calcif Tissue Int. 1990;47(4):194-201.

14. Prince RL, Devine A, Dhaliwal SS, Dick IM. Effects of calcium supplementation on clinical fracture and bone structure: results of a 5-year, double-blind, placebo-controlled trial in elderly women. Arch Intern Med. 2006;166(8):869-875.

15. Larsen ER, Mosekilde L, Foldspang A. Vitamin D and calcium supplementation prevents osteoporotic fractures in elderly community dwelling residents: a pragmatic population-based 3-year intervention study. J Bone Miner Res. 2004;19(3):370-378.

16. Chapuy MC, Pamphile R, Paris E, et al. Combined calcium and vitamin D3 supplementation in elderly women: confirmation of reversal of secondary hyperparathyroidism and hip fracture risk: the Decalyos II study. Osteoporos Int. 2002;13(3):257-264.

17. Dawson-Hughes B, Harris SS, Krall EA, Dallal GE. Effect of calcium and vitamin D supplementation on bone density in men and women 65 years of age or older. $N$ Engl J Med. 1997;337(10):670-676.

18. Resch H, Walliser J, Phillips S, Wehren LE, Sen SS. Physician and patient perceptions on the use of vitamin $\mathrm{D}$ and calcium in osteoporosis treatment: a European and Latin American perspective. Curr Med Res Opin. 2007;23(6):1227-1237.

19. Bruyère O, Malaise O, Neuprez A, Collette J, Reginster JY. Prevalence of vitamin D inadequacy in European postmenopausal women. Curr Med Res Opin. 2007;23(8):1939-1944.

20. Moniz C, Dew T, Dixon T. Prevalence of vitamin D inadequacy in osteoporotic hip fracture patients in London. Curr Med Res Opin. 2005; 21(12):1891-1894.

21. Neuprez A, Bruyère $\mathrm{O}$, Collette J, Reginster JY. Vitamin D inadequacy in Belgian postmenopausal osteoporotic women. BMC Public Health. 2007;7:64.

22. Gaugris S, Heaney RP, Boonen S, Kurth H, Bentkover JD, Sen SS. Vitamin D inadequacy among post-menopausal women: a systematic review. QJM. 2005;98(9):667-676.

23. Vieth R, Ladak Y, Walfish PG. Age-related changes in the 25-hydroxyvitamin D versus parathyroid hormone relationship suggest a different reason why older adults require more vitamin D. $J$ Clin Endocrinol Metab. 2003;88(1):185-191.

24. Hercberg S, Galan P, Preziosi P, et al. The SU.VI.MAX study: a randomized, placebo-controlled trial of the health effects of antioxidant vitamins and minerals. Arch Intern Med. 2004;164(21):2335-2342.

25. Fan T, Bogle S, Nocea G, Sen SS. Validity and reproducibility of questionnaire about preventive behaviors among French and Spanish postmenopausal women with osteoporosis in the Calcium and Vitamin Intake (CaVit) Study. Calcif Tissue Int. 2008;82:S188.

26. Blalock SJ, Norton LL, Patel RA, Cabral K, Thomas CL. Development and assessment of a short instrument for assessing dietary intakes of calcium and vitamin D. J Am Pharm Assoc (2003). 2003;43(6):685-693.

27. Kesse E, Bertrais S, Astorg P, et al. Dairy products, calcium and phosphorus intake, and the risk of prostate cancer: results of the French prospective SU.VI.MAX (Supplémentation en Vitamines et Minéraux Antioxydants) study. Br J Nutr. 2006;95(3):539-545. 
28. Kesse-Guyot E, Bertrais S, Duperray B, et al. Dairy products, calcium and the risk of breast cancer: results of the French SU.VI.MAX prospective study. Ann Nutr Metab. 2007;51(2):139-145.

29. Suzuki Y, Whiting SJ, Davison KS, Chilibeck PD. Total calcium intake is associated with cortical bone mineral density in a cohort of postmenopausal women not taking estrogen. $J$ Nutr Health Aging. 2003;7:296-299.

30. International Osteoporosis Foundation. "Vitamin D." Available from: http://www.iofbonehealth.org/vitamin-d-0. Accessed April 5, 2013.

31. Serra-Majem L, Aranceta J; SENC Working Group on Nutritional Objectives for the Spanish Population. Spanish Society of Community Nutrition. Nutritional objectives for the Spanish population. Consensus from the Spanish Society of Community Nutrition. Public Health Nutr. 2001;4(6A):1409-1413.

32. Food and Agriculture Organization of the United Nations (FAO). Human Vitamin and Mineral Requirements: Report of a Joint FAO/ WHO Expert Consultation Bangkok, Thailand. Rome: FAO; 2001. Available from: ftp://ftp.fao.org/es/esn/nutrition/Vitrni/pdf/TOTAL. pdf. Accessed March 11, 2013.

33. Vaqueiro M, Bare M, Anton E, et al. Hypovitaminosis D associated to low sun exposure in the population over 64 years old. Med Clin (Barc). 2007;129(8):287-291. Spanish.

34. Vaquero MP, Sánchez-Muniz FJ, Carbajal A, García-Linares MC, García-Fernández MC, García-Arias MT. Mineral and vitamin status in elderly persons from Northwest Spain consuming an Atlantic variant of the Mediterranean diet. Ann Nutr Metab. 2004;48(3):125-133.

35. Pérez-Llamas F, López-Contreras MJ, Blanco MJ, López-Azorín F, Zamora S, Moreiras O. Seemingly paradoxical seasonal influences on vitamin D status in nursing-home elderly people from a Mediterranean area. Nutrition. 2008;24(5):414-420.

36. Ubeda N, Basagoiti M, Alonso-Aperte E, Varela-Moreiras G. Dietary food habits, nutritional status and lifestyle in menopausal women in Spain. Nutr Hosp. 2007;22(3):313-321. Spanish.
37. Serra-Majem L, Ribas-Barba L, Salvador G, et al. Trends in energy and nutrient intake and risk of inadequate intakes in Catalonia, Spain (1992-2003). Public Health Nutr. 2007;10(11A):1354-1367.

38. Jodral-Segado AM, Navarro-Alarcón M, López-Ga de la Serrana H, López-Martínez MC. Magnesium and calcium contents in foods from SE Spain: influencing factors and estimation of daily dietary intakes. Sci Total Environ. 2003;312(1-3):47-58.

39. Orozco López P, Zwart Salmerón M, Vilert Garrofa E, Olmos Domínguez C; INDICAD Study 2001. Prediction of the total calcium intake from consumption of milk products in Spain adult population. INDICAD Study 2001. Aten Primaria. 2004;33(5):237-243. Spanish.

40. Brown SE. Vitamin D and fracture reduction: an evaluation of the existing research. Altern Med Rev. 2008;13(1):21-33.

41. Seiquer I, Mesías M, Hoyos AM, Galdó G, Navarro MP. A Mediterranean dietary style improves calcium utilization in healthy male adolescents. J Am Coll Nutr. 2008;27(4):454-462.

42. Mataix J, Aranda P, López-Jurado M, Sánchez C, Planells E, Llopis J. Factors influencing the intake and plasma levels of calcium, phosphorus and magnesium in southern Spain. Eur J Nutr. 2006;45(6):349-354.

43. Gennari L, Bilezikian JP. Osteoporosis in men. Endocrinol Metab Clin North Am. 2007;36(2):399-419.

44. Jackson RD, LaCroix AZ, Gass M, et al. Calcium plus vitamin D supplementation and the risk of fractures. N Engl J Med. 2006;354(7): 669-683.

45. Grant AM, Avenell A, Campbell MK, et al; RECORD Trial Group. Oral vitamin D3 and calcium for secondary prevention of low-trauma fractures in elderly people (Randomised Evaluation of Calcium Or vitamin D, RECORD): a randomised placebo-controlled trial. Lancet. 2005;365(9471):1621-1628.
Clinical Interventions in Aging

\section{Publish your work in this journal}

Clinical Interventions in Aging is an international, peer-reviewed journal focusing on evidence-based reports on the value or lack thereof of treatments intended to prevent or delay the onset of maladaptive correlates of aging in human beings. This journal is indexed on PubMed Central, MedLine, the American Chemical Society's 'Chemical Abstracts Ser-

\section{Dovepress}

vice' (CAS), Scopus and the Elsevier Bibliographic databases. The manuscript management system is completely online and includes a very quick and fair peer-review system, which is all easy to use. Visit http://www.dovepress.com/testimonials.php to read real quotes from published authors. 